\title{
Exuberant clinical picture of Buschke-Fischer-Brauer palmoplantar keratoderma in bedridden patient ${ }^{*}$
}

\author{
João Roberto Antonio ${ }^{1,2}$ \\ Natalia Cristina Pires Rossi ${ }^{1}$ \\ Gustavo Bueno de Oliveira ${ }^{3}$
}

\author{
Guilherme Bueno de Oliveira ${ }^{1}$ \\ Laiza Gabriela Garcia Pires ${ }^{1}$
}

DOI: http://dx.doi.org/10.1590/abd1806-4841.20142923

\begin{abstract}
Buschke-Fisher-Brauer keratoderma is a rare hereditary autosomal dominant disease of incomplete penetrance. Important differential diagnoses include other palmoplantar keratinization disorders, acquired or hereditary, which is done based on the histopathological findings. This diagnosis alerts especially about the possibility of associated neoplasms. Treatment involves topical keratolytic agents, usually with little efficacy, or with long-term systemic retinoids with follow-up of exuberant collateral effects.
\end{abstract}

Keywords: Dermatology; Keratoderma, palmoplantar; Skin diseases, genetic

\section{INTRODUCTION}

Palmoplantar keratodermas (PPK) are due to hyperproliferation of the stratum corneum of the epidermis in palmar and plantar regions, which may be secondary to a hereditary or acquired origin. The hereditary ones group themselves according to the transmission mode, clinical presentation (focal, punctate or diffuse) and the presence of dermatological or non-dermatological associated alterations. ${ }^{1}$

The Buschke-Fischer-Brauer keratoderma was described for the first time in 1879 as "Disseminated clavus of the hands and feet"1. In 1910, Buschke and Fischer documented the disease and named it "Keratoderma maculosa disseminata palmaris et plantaris". ${ }^{2}$ In 1913, Brauer demonstrated the hereditary nature of the disease which from then on was called "Buschke-Fischer-Brauer palmoplantar keratoderma" ${ }^{3,4}$ In 2005, a study done in China evidenced a region of 5,06-cM in chromosome 15q22.2-15q22.31 as the genetic locus of the syndrome. ${ }^{4}$ This disease has an estimated prevalence of $1.17 / 100,000 .^{2}$ Its clinical presentation happens mainly at the end of infancy and adolescence; however, there are reports of late onset, in the fifth decade of life, at an average of 12 to 33 years of age. ${ }^{4,5}$

Clinically, it presents with numerous and tiny hyperkeratotic papules on the entire palmoplantar sur- face. In locations of greater pressure on the sole of the foot, the lesions are prone to coalescence and a more diffuse pattern. ${ }^{4,5}$ This probably occurs due to the constant friction on these regions, the plantar region due to deambulation and palmar region due to actions performed by hand, like work or leisure activities.

The majority of the diagnoses is done incidentally due to the asymptomatic nature of the syndrome, eventually presenting only an increase of sensitivity in sites of greater pressure. ${ }^{5}$

Another important characteristic is the association of Buschke-Fischer-Brauer keratoderma with other abnormalities, such as malignancies - colon adenocarcinoma, prostate cancer, breast cancer and metastatic non-small cell lung cancer, neurological alterations, nail dystrophies, psoriasis and keratosis pilaris. ${ }^{2,-7}$

\section{CASE REPORT}

A 75-year-old patient, male, white, bedridden for 15 years due to a cerebrovascular accident (CVA) sequela, reports painful and hardened lesions in the palmoplantar region since childhood with worsening after being bedridden. He also reported having two children with the same clinical picture.

At the dermatological exam, he presents keratotic papules and cutaneous horns on the palmoplan-

Received on 09.07.2013.

Approved by the Advisory Board and accepted for publication on 13.09.2013.

* Work performed at Faculdade de Medicina de São José do Rio Preto (FAMERP) - São José do Rio Preto (SP) - Brazil.

Conflict of interest: None

Financial funding: None

Faculdade de Medicina de São José do Rio Preto (FAMERP) - São José do Rio Preto (SP) - Brazil

Hospital de Base - São José do Rio Preto (SP) - Brazil.

Universidade São Francisco de Bragança Paulista (USF) - Bragança Paulista (SP), Brazil.

CC2014 by Anais Brasileiros de Dermatologia

An Bras Dermatol. 2014;89(5):819-21. 
tar region (Figures 1, 2 and 3). His daughter has the same clinical picture of palmoplantar keratotic papules, but plane instead. The anatomopathological exam of the lesion evidenced hyperkeratosis, orthokeratosis and acanthosis without koilocytosis.

The worsening and exacerbation of lesions are probably explained by the sequelar clinical picture of diminised movement due to the CVA. The impossibility of deambulation and performance of daily labor activities, leisure or other needs led to the decrease of friction of keratotic papules, enabling the formation of cutaneous horns in the palmoplantar region of this patient.

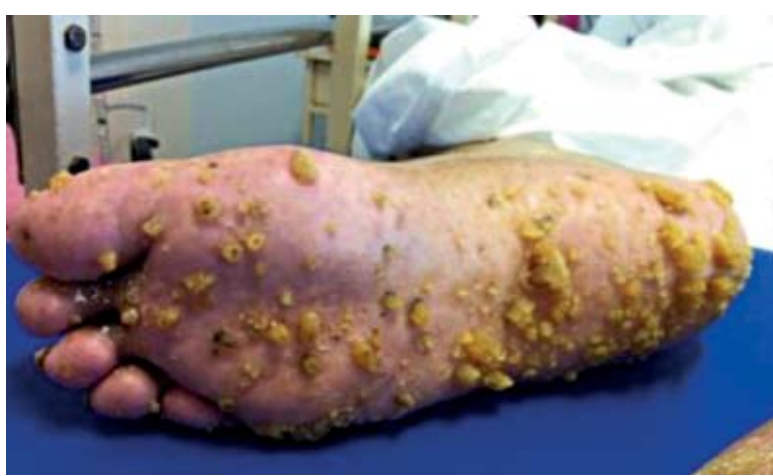

FIGURE 1: Keratotic papules and cutaneous horns on right plantar region

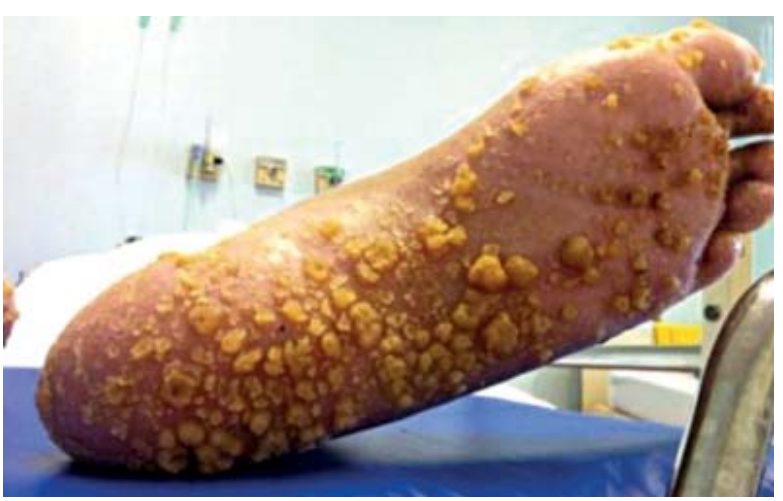

FIGURE 2: Keratotic papules and cutaneous horns on left plantar region

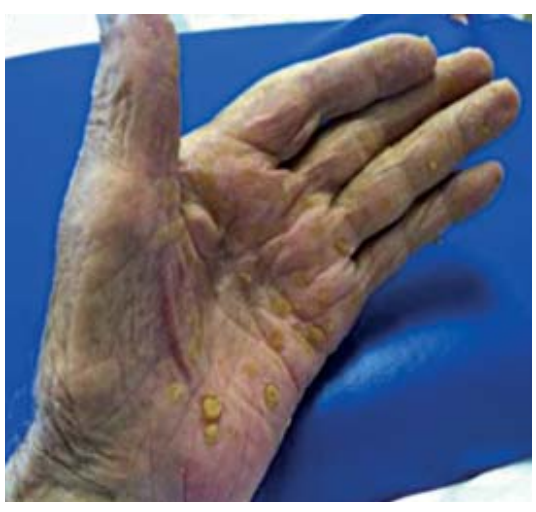

FIGURE 3:

Keratotic papules and cutaneous horns on left palmar region

\section{DISCUSSION}

The palmoplantar keratodermas are a permanent thickening of the stratum corneum of palms and/or soles. They represent a group of acquired or hereditary diseases. The hereditary ones are grouped into three forms based on morphology (diffuse, punctate or focal), mode of transmission and by the association of dermatological or extra-dermatological alterations. ${ }^{1}$ The palmoplantar keratoderma of BuschkeFischer-Brauer is a hereditary autosomal dominant disease of incomplete penetrance, whose genetic locus was found in a $5.06 \mathrm{cM}$ region in $15 \mathrm{q} 22.2-15 \mathrm{q} 22.31{ }^{1,4} \mathrm{It}$ is a rare disease, with prevalence of $1.17 / 100,000$ in Croatia, manifested in the 12 to 30 years age group, with no difference between sexes, although predominance in males is reported..$^{1,5}$

It is clinically characterized by hyperkeratotic papular lesions, punctate, irregularly distributed on palms and soles, converging into yellowish plaques in sites of greater pressure and friction. ${ }^{1,8}$ At one extreme, the papules acquire a verrucoid aspect or of cutaneous horns, especially when some factor diminishes the degree of pressure or compression over lesions, as was evidenced in this patient. Usually asymptomatic, they may however generate pain in the pressure zones and make palmar grasp and walking difficult. ${ }^{8}$ In the above mentioned case, the lesions were similar to cutaneous horns, showing an exuberant clinical picture of the disease, due to the fact that the patient remains bedridden, with no friction mechanisms responsible for the planing of lesions.

Nail alterations are common: nail thickening, dyschromia, subungual hyperkeratosis, hemorrhages, onychogryposis, onychomadesis, onychorrhexis, grooves, cracks, among others; however, these are nonspecific manifestations, as well as the association with hyperhidrosis. ${ }^{1,2,3,6,8}$

Important differential diagnoses are exposure to arsenic, verruca vulgaris, acrokeratoelastoidosis of Costa, punctate porokeratotic keratoderma and focal acral hyperkeratosis, lichen planus and painful calluses disease, which show respectively: mild to moderate keratinocytic dysplasia, koilocytosis, focal hyperkeratosis with elastorrhexis, parakeratotic columns with hyperkeratosis, focal hyperkeratosis without elastorrhexis, vacuolization of the basal layer and epidermolysis. ${ }^{1,2,3,5,9,10}$ In palmoplantar keratoderma of BuschkeFischer-Brauer, histology reveals thickening of the horny layer, flattening of the underlying structures and non-specific alterations such as parakeratosis and acanthosis. ${ }^{1,2,9,10}$

There is an association with neoplasms, especially of the digestive tract, like pancreas, colon adenocarcinoma, besides renal and mammary neoplasms. ${ }^{2,5,8}$ There is also a report of association with 
psoriasis, keratosis pilaris, arthropathy related to HLA-B27. ${ }^{2,5,7}$

The treatment is administered with keratolytic agents, such as topical salicylic acid especially in asymptomatic clinical pictures; debridement, excision as alternatives to temporary relief of cutaneous thickening and systemic retinoids, like acitretin in more severe and symptomatic cases, which shows better results; nevertheless, it has important adverse effects which may lead to discontinuation of treatment. $1,2,5,8,9$ Such agents may demonstrate considerable improvement, although a long-term treatment is needed. Relapses may occur. ${ }^{8}$

\section{REFERENCES}

1. El Amri I, Mamai O, Ghariani N, Denguezli M, Sriha B, Adala L, et al. Étude clinique et génétique de la kératodermie palmoplantaire de Buschke-Fischer-Brauer dans une famille tunisienne. Ann Dermatol Venereol. 2010;137:269-75.

2. Oztas P, Alli N, Polat M, Dagdelen S, Ustün H, Artüz F, et al. Punctate Palmoplantar Keratoderma (Brauer-Buschke-Fischer Syndrome). Am J Clin Dermatol. 2007;8:113-6.

3. Gupta R, Mehta S, Pandhi D, Singal A. Hereditary punctate palmoplantar keratoderma (PPK) [Brauer-Buschke-Fischer syndrome]. J Dermatol. 2004;31398-402.

4. Gao M, Yang S, Li M, Yan KL, Jiang YX, Cui Y, et al. Refined localization of a punctate palmoplantar keratoderma gene to a 5.06-cM region at 15q22.2-15q22.31. $\mathrm{Br}$ J Dermatol. 2005;152:874-8.

5. Al-Mutairi N, Joshi A, Nour-Eldin 0. Punctate Palmoplantar Keratoderma (BuschkeFischer-Brauer Disease) with Psoriasis: A Rare Association Showing Excellent Response to Acitretin. J Drugs Dermatol. 2005;4:627-34.

6. Inamadar AC, Palit A. Nails: Diagnostic clue to genodermatoses. Indian J Dermatol Venereol Leprol. 2012;78:271-8.

7. Kumari R, Thappa D. Keratosis palmoplantaris punctata (Buschke-Fischer-Brauer) with keratosis pilaris. Indian J Dermatol. 2006; 51: 223-4.

8. Lopes CF. O Etretinato - Uso clínico. An Bras Dermatol. 1986;61:29-36.

9. Lopes CF. 0 uso de retinóides em algumas dermatoses com exceção de psoríase e acne. An Bras Dermatol. 1988;63:309-12.

10. Stevens HP, Kelsell DP, Leigh IM. The inherited keratodermas of palms and soles. In: Freedberg IM, Eisen AZ, Wolff K, Austen K, Goldsmith LA, Katz SI, editors. Fitzpatrick's dermatology in general medicine. 6th ed. New York: McGraw-Hill, 2003. p.505-14.

\author{
MAILING ADDRESS: \\ João Roberto Antonio \\ Av. Brigadeiro Faria Lima, 5416 \\ Vila São Pedro \\ 15090-000 - São José do Rio Preto - SP \\ Brazil \\ E-mail:dr.joao@terra.com.br
}

How to cite this article: Antonio JR, Oliveira GB, Rossi NCP, Pires LGG, Oliveira GB. Exuberant clinical picture of Buschke-Fischer-Brauer palmoplantar keratoderma in bedridden patient. An Bras Dermatol. 2014;89(5):819-21. 